\title{
A CRISE DA HUMANIDADE E A CRÍTICA RADICAL DO VALOR ${ }^{1}$
}

\author{
Denis Collin*
}

\begin{abstract}
A crise atual não é simplesmente uma crise econômica. É uma crise global que afeta todos os aspectos da vida humana em uma escala mundial. O sistema baseado na acumulação ilimitada de capital não pode mais ser perpetuado sem ameaçar a própria civilização. Neste sentido, é uma crise da humanidade, muito mais do que uma crise econômica. A retomada de conceitoschave marxianos nos permite compreender sua seriedade e profundidade.

Palavras-Chave: Acumulação de capital. Agricultura. Crise. Regulação. Sistema monetário internacional.
\end{abstract}

Desde o início da crise dos subprimes, em 2007, a fragilidade do sistema financeiro mundial é patente. Mas estaríamos errados em ver nisso apenas um avatar da boa e velha crise econômica para a qual dispomos de uma pletora de análises. Precisamente, não se trata, apenas, de economia, ou não. Para compreender suas causas e profundidade, é preciso passar pela crítica da economia política, ou seja, por Marx. A partir disso, poderemos compreender que se trata, apenas, da manifestação de uma crise global de relações de produção fundadas sobre a mercadoria e a acumulação do capital, uma crise que engloba todos os aspectos da vida e levanta a questão da própria sobrevivência da humanidade no próximo século.

* Doutor em Literatura e Humanidades. Professor da Université de Rouen et Lycée Briand Évreux. 11 rue de Bretagne. 27000 - Evreux - France. denis.collin@live.fr

${ }^{1}$ Tradução de George Mascarenhas. Revisão técnica, Jorge Nóvoa.

\section{AFEBRE ESPECULATIVA}

Vários autores analisam a crise atual do modo de produção capitalista como a crise da financeirização da economia que se seguiu à fase de três décadas após a segunda guerra mundial, uma fase que termina, oficialmente, com a declaração de Nixon de 15 de agosto de 1971, anunciando o fim do sistema monetário internacional de Bretton Wood com a inconversibilidade do dólar em ouro. É, evidentemente, uma questão importante na compreensão da realidade atual, contanto que se compreenda sua extensão mais global.

As crises financeiras fazem parte do desenvolvimento normal do modo de produção capitalista desde que ele existe. Encontramos, por exemplo, uma descrição surpreendente disso no romance de Émile Zola, $O$ dinheiro. Mas, até agora, a febre especulativa aparecia como um estado adoecido do modo de produção capitalista que a crise viria purgar. A especulação financeira, hoje em dia, não é mais nem passageira, nem limitada à camada superior do capitalismo, ela tende a se tornar seu modo de funcionamento normal; toda pro- 
dução é submetida a ela e só existe como uma variante de investimentos financeiros possíveis. Como, progressivamente, todas as fronteiras prudenciais caíram, todo mundo pode especular. Os bancos de depósito solicitam a seus clientes, mesmo os mais modestos, que se lancem no grande jogo da especulação. Os hipermercados vendem seguros e investimentos financeiros. A liberalização e a mundialização que se desenvolveram simultaneamente, reforçando-se mutuamente, do final dos anos 70 até hoje, foram os meios desta expansão e desta dominação da esfera financeira sobre o conjunto da economia.

Em agosto de 1971, Richard Nixon abria um novo período, declarando a inconversibilidade do dólar em ouro. Até então, a moeda americana funcionava como moeda internacional porque era, supostamente, "as good as gold" ["tão boa quanto ouro"]: uma onça (mais ou menos $30 \mathrm{~g}$ ) de ouro era representada por 35 dólares. A partir da declaração de Nixon, o dólar é, apenas, uma "moeda de papel" de curso forçado. A crise do sistema monetário internacional abrirá o caminho para a especulação financeira com o estabelecimento, no final dos anos 70, dos câmbios flutuantes, com a desmonetização do ouro e o desenvolvimento de operações com eurodólares-dólares em posse de bancos europeus, principalmente ingleses ou soviéticos.

Estes eventos levarão os Estados a mudar sua política econômica e a abandonar os princípios de regulação que marcaram o período anterior. Paul Volcker, o diretor do FED americano, impulsionará a virada monetarista que encontrará sua expressão política na reaganomia e na política de Mrs. Thatcher. O que dominará essas políticas, executadas pelos Estados mais potentes, que mostraram, portanto, deste ponto de vista, a eficácia do político sobre o econômico, é a desregulamentação financeira: notadamente, são progressivamente suprimidas todas as separações existentes entre os diversos tipos de estabelecimentos bancários e financeiros, separações que foram estabelecidas depois da crise de 1929, para evitar um novo crash.

Em seguida, em virtude mesmo da instabilidade que o sistema de câmbios flutuantes cria e da desregulamentação em curso, os produtos derivados se multiplicarão, notadamente os produtos que permitem garantias contra os riscos de prazo. Enfim, e de acordo com os dogmas monetaristas, a única regulação subsistente será a regulação pela massa monetária e pela política de taxas de juros elevados. Assim, enquanto que o período precedente foi marcado pelas taxas baixas e, às vezes, até negativas (levando-se em conta a inflação), o novo período será um período de taxas reais elevadas, chegando a $6 \%$ em certos períodos, o que, praticamente, nunca tinha sido visto antes em toda a história do capitalismo. O capital portador de juros sangra até a última gota toda a economia "real".

Esta nova fase do modo de produção capitalista parece ter tetanizado a opinião e os especialistas da esquerda tradicional; graças à teoria keynesiana, eles descobriram um corpus teórico alternativo ao corpus marxista. Ao desregular as condições de funcionamento do modo de produção capitalista, a fase monetarista/desreguladora, que se abre no fim dos anos 70, solapa as bases do edifício da política socialdemocrata. A ideia de que os interesses dos trabalhadores e os interesses dos capitalistas pudessem ser reconciliados, a longo prazo, em um modo de acumulação fundado sobre a partilha dos ganhos de produtividade, ficou doravante destituída de qualquer base séria.

A constituição de um mercado financeiro unificado em escala mundial não é estranha. Ela corresponde ao desenvolvimento do "capital fictício", cujos títulos de empréstimo do Estado constituem sua forma mais acabada. O capital financeiro pode se dividir em duas categorias que confundimos habitualmente e que, todavia, são, quanto à sua natureza, radicalmente diferentes:

1. os empréstimos a médio e longo prazo, que financiam os investimentos produtivos e cujos juros que recobram não são mais do que uma dedução sobre a mais-valia produzida no processo de produção.

2. o capital "fictício", que é representado pelos créditos cambiáveis por engajamentos futuros de tesouros públicos, cujo valor é inteiramente derivado da capitalização de ganhos antecipados sem 
contrapartida direta em capital produtivo.

Sigamos, por um instante, o raciocínio de Marx: "A forma do capital produtivo de juros faz com que toda renda monetária determinada e regular pareçam juros de um capital, provindo ou não de um capital". ${ }^{2} \mathrm{O}$ "capital fictício" se funda sobre uma operação intelectual retrospectiva, que supõe uma inversão dos meios e dos fins, operação própria do processo de produção de representações ideológicas. "A receita monetária é, primeiro, transformada em juros e, a partir disso, encontramos igualmente o capital que é a sua origem”. Marx se contenta, aqui, em descrever o funcionamento concreto do modo de produção capitalista. Assim, o preço de venda de um bem imobiliário é calculado, considerando-se que este bem é um capital portador de juros, estes representados pelo aluguel. Mas este processo tem uma consequência importante: "toda soma de valor aparece como capital, desde que não seja gasta como renda; ela aparece como soma principal, em contraste com os juros possíveis ou reais que é capaz de produzir". ${ }^{3}$

O exemplo da dívida do Estado é particularmente esclarecedor quanto às consequências do processo: "O Estado deve pagar todo ano a seus credores certa soma de juros pelo capital emprestado. Nestes casos, o credor não pode cancelar seu empréstimo, mas pode vender seus créditos, o título que assegura sua titularidade. O próprio capital foi consumido, gasto pelo Estado. Ele não existe mais". ${ }^{4}$ O que o credor possui é: (1) um título de propriedade; (2) o que é resultante dele, o direito a uma retirada anual sobre o produto dos impostos; e (3) o direito de vender este título. "Mas em todos esses casos, o capital que deve supostamente produzir um fruto (juros) - o pagamento do Estado é um capital ilusório, fictício. É que a soma emprestada ao Estado não apenas não existe mais, mas nunca foi destinada a ser gasta como capital". ${ }^{5}$ Para o credor, emprestar dinheiro ao Estado

\footnotetext{
${ }^{2}$ Marx, O Capital, livro III, seção V, édition de La Pléiade, v. 2, p. 1191.

${ }^{3}$ Ibid.

${ }^{4}$ Op. cit. p. 1192

${ }^{5}$ Ibid.
}

para obter uma parte do produto do imposto, ou emprestar dinheiro ao industrial calculado a juros médios, ou, ainda, comprar ações com o propósito de receber os dividendos são operações equivalentes. "Mas o capital da dívida pública não é menos puramente fictício e quando as obrigações se tornam invendáveis, é o próprio fim da aparência deste capital". É precisamente o que aconteceu com a crise da Grécia, da Espanha ou de Portugal. E é o que registram as agências de classificação de risco, degradando a nota dessas dívidas soberanas.

Mas a dívida pública não é a única forma de capital fictício. O "capital monetário fictício" compreende todas as variedades de títulos monetários portadores de juros na medida em que eles circulam na Bolsa tanto quanto as ações. É preciso acrescentar os múltiplos novos produtos financeiros que, sem exceção, sob uma forma ou outra, visam titularizar o crédito e fazer circular títulos de crédito como capital. Nesta categoria, devemos incluir os produtos de alto risco, como os junk bonds, obrigações de risco elevado, na medida em que são assentadas sobre recebíveis duvidosos. Os subprimes, evidentemente, faziam parte destes créditos "podres". De modo mais geral, a "prosperidade" imobiliária da Espanha e de Portugal repousava sobre as mesmas bases, até que se percebesse que as casas não encontrariam mais compradores ou que os compradores se encontravam na impossibilidade de pagar os empréstimos.

Enquanto a alusão feita por Marx à moeda de crédito como capital fictício concernia unicamente à moeda fiduciária não coberta pelas reservas de ouro, hoje em dia, nós operamos, exclusivamente, com a moeda sob esta forma. $\mathrm{E}$, em consequência disso, é a própria moeda que deve ser considerada como "forma do capital fictício". Centenas de bilhões de dólares, contabilizados como riqueza real, se deslocam de um lugar financeiro para o outro, sem encontrar emprego em um nível de rentabilidade suficiente.

É a própria dinâmica do modo de produção capitalista, tal como Marx analisou, que tende a esta financeirização da economia. Não se trata, 
portanto, de um acidente ou de má política dos gestores capitalistas, mas de uma tendência pesada, imanente a esta relação social, que é o capital. O parasitismo crescente desta "economia política do rentista" (para retomar a expressão de Boukharine $^{6}$ ) bem como o apagamento progressivo da distinção entre os negócios saudáveis e os negócios fraudulentos são as consequências inelutáveis destes processos que afetam as próprias bases da economia. Que as máfias tenham desempenhado um papel central na introdução do capitalismo na Europa do Leste e na União Soviética, não é simplesmente um traço contingente, um resultado da história específica de determinados países (a máfia está longe de ser uma especialidade siciliana!), mas uma das dimensões essenciais do capitalismo em seu conjunto. Para se convencer, basta conhecer os rendimentos fabulosos do comércio de drogas e, de modo mais geral, de todos os negócios ilícitos, cujos rendimentos são, em seguida, reciclados para a economia "saudável”. O desenvolvimento da esfera financeira tende a tornar-se incontrolável.

O mercado financeiro concerne às operações de financiamento das atividades das empresas (empréstimos em bancos, emissão de obrigações, etc.). O mercado de câmbio concentra a especulação sobre as moedas. Enfim, o mercado dos produtos derivados, que progressivamente inundaram toda a esfera financeira, é este mercado de opções do qual fala Galbraith a propósito dos terrenos na Flórida. ${ }^{7}$ Vemos que as transações que concernem à "economia real" representam somente uma parte fraca dos mercados financeiros (pouco mais de 2\%): levantar fundos para construir uma nova fábrica, pagar patentes ou comprar novas máquinas, visivelmente, não é mais o que ocupa o capitalismo do terceiro milênio. O que é ainda mais surpreendente é o extraordinário crescimento dos mercados derivados. Ora, estes mercados correspondem, essencialmente, a operações de

${ }^{6}$ Ver N. Boukharine, L'économie politique du rentier. Critique de l'économie marginaliste. Réédition Syllepse, 2010.

${ }^{7}$ Ver J.K. Galbraith, La crise économique de 1929, éditions Payot, 1989 "cobertura": uma empresa que planeja comprar uma certa quantidade de matéria-prima em três meses pode se precaver contra uma alta de preços fazendo uma promessa de compra com um intermediário que se compromete a fornecer-lhe a quantidade de mercadoria exigida no preço exigido. Se, na data $\mathrm{D}+3$ meses, o preço das matérias primas tiver reduzido, o intermediário embolsa o lucro; se o preço for o previsto, ele se contentará com uma comissão e, se as matérias-primas tiverem aumentado, ele pagará a diferença de seu bolso. É, de fato, um mercado de seguros de operações de compra e venda nos mercados reais ou nos mercados de transações financeiras. É, no mínimo, curioso ver que, no mesmo momento em que as ideologias exaltam o risco em nome da fluidez dos mercados, desenvolve-se, de maneira totalmente incontrolável, este mercado de seguro nas áleas do capitalismo.

Tais montantes não correspondem, evidentemente, a riquezas reais. Se eu passar o dia trocando cédulas de 10 euros pelo equivalente em dólares com meu amigo, no fim do dia nós teremos um montante acumulado de transações realmente fabulosas, mas nada terá acontecido, exceto, contingencialmente, perdas e ganhos de um lado ou do outro. Mas esta riqueza fictícia tem efeitos bastante reais, mesmo que sejam apenas limitados no tempo, e oferece um poder de agir e de dispor do produto social excedente. Vez que esses mercados derivados não criam, decerto, nenhuma riqueza nova - seus defensores mais caridosos podem, eventualmente, fazer a concessão de que eles facilitam a tomada de risco e, portanto, a criação de riquezas - e vivem apenas de punções que operam na mais-valia global.

A financeirização geral do capital não é somente, por conseguinte, uma fonte de injustiça crescente, empurrando as desigualdades sociais e as desigualdades entre as diversas nações a um ponto que, sem dúvida, nunca tinha sido atingido antes, no curso da história. $O$ frenesi que reina sobre os mercados, a impossibilidade em que se encontram os que estão no poder de calcular um prazo, menor que seja, parece comprometer toda tentativa que vise favorecer a estabilidade macroeconômica mínima 
exigida pela acumulação.

É preciso, no entanto, não se deixar prender às descrições que enfatizam a especulação e que fazem da economia atual uma economia puramente parasitária. O parasitismo só pode se desenvolver na condição de que haja um corpo vivo a ser parasitado. A especulação só é possível se o corpo vivo da economia real permitir. Michel Husson observa que "os discursos sobre a economia-cassino fornecem descrições úteis e críticas operacionais, mas que não vão profundamente à raiz das coisas. O limite principal de muitas abordagens, mesmo aquelas que se dizem críticas, é de não romper com um certo fetichismo da finança". ${ }^{8}$

Este discurso, com efeito, leva a considerar as representações da riqueza como a riqueza real, as grandezas virtuais, confundindo, por exemplo, a soma das transações, geralmente eletrônicas, efetuadas em um dia, no conjunto das praças financeiras que operam continuamente - as praças ocidentais substituindo Hong Kong e Singapuracom as grandezas reais, as trocas de automóvel, de computadores, de trigo e de calçados esportivos. É precisamente neste gênero de fantasmagoria que caem, frequentemente, os defensores fanáticos das redes, da mundialização e da manipulação de símbolos que substitui a manipulação de coisas, da realidade virtual que suplanta a realidade material e outros disparates da mesma espécie.

A financeirização da economia não constitui um aumento da riqueza real global, mas uma gigantesca transferência de riquezas dos assalariados, seja diretamente sob a forma de redução dos salários, seja indiretamente pela demissão de uma parte dos assalariados e o agravamento da exploração daqueles que ainda têm a sorte de ter um trabalho - para a classe capitalista, no sentido amplo, incluindo uma parte das classes médias que vivem diretamente ou indiretamente desta financeirização, através da renda decorrente que pode rapidamente ser substancial, ou pelas profissões ligadas a esta explosão dos mercados financeiros, ou, ainda, pelo desenvolvimento de

8 Husson, Michel, Les trois dimensions du néoimpérialisme, in revue "Actuel Marx", n.18, 1995. atividades parasitárias ligadas à comunicação, à publicidade, etc.

Os Estados, longe de serem vítimas de uma mundialização financeira que não podem dominar, são, ao contrário, seus maiores atores. Seu endividamento, que parece catastrófico ao contribuinte, é, ao contrário, uma benção para o especulador, vez que a dívida pública é uma das primeiras alavancas que permitem essa transferência de rendimentos da classe operária para a renda financeira. Com efeito, a financeirização do mundo é, antes de tudo, um impulso espetacular das operações com títulos da dívida pública. Entre 1980 e 1993, nos Estados Unidos, passamos de uma média diária de 13,8 bilhões de dólares a 119,6 bilhões de dólares; na França, para o período 1986/ 1993, passamos de 200 milhões de dólares a 13,7 bilhões. A crise da zona do euro, com a catástrofe grega, é, apenas, o coroamento deste processo. Para evitar o colapso de todo o sistema financeiro, os países da zona do euro garantiram os bancos e assumiram a falência virtual destas instituições financeiras. Assim, enquanto os Estados pagam as dívidas com taxas muito elevadas, o Banco Central Europeu refinancia os bancos a $0 \%$ e, às vezes, até com taxas negativas, e os bancos podem, em seguida, refinanciar com taxas altas ( $5 \%$ ou $6 \%$ ) os Estados endividados.

As altas taxas de juros tornam particularmente interessantes os investimentos financeiros, principalmente nos empréstimos de Estado, títulos do tesouro, etc. e, ao mesmo tempo, aumentam a dívida pública, já que, em virtude destas taxas de juros, o pagamento da dívida ocupa uma parte crescente nos orçamentos públicos. Pela mesma razão, as necessidades de financiamento dos Estados aumentam, o que empurra as taxas de juros para o alto. É este mecanismo infernal que os célebres “critérios de Maastricht" executam. Eles parecem ter sido feitos sob medida para as necessidades da especulação. O mecanismo europeu de estabilização, definido com a regra de ouro, fixa em 3\% do PIB o déficit máximo das contas públicas e visa impor o controle da burocracia europeísta dos orçamentos de todos os Estados. Isso tem, 
como primeiro efeito, o afundamento das nações na depressão econômica. Quanto mais se obriga a Grécia a pagar sua dívida, sob as chicotadas da troica (UE, FMI, Banco Europeu), mais a Grécia se encontra na incapacidade de pagá-la. Tendo praticamente dividido os salários dos funcionários pela metade e retalhado as pensões, demitido centenas de milhares de trabalhadores, esquartejado o sistema de saúde, a Grécia estará, sem dúvida, irremediavelmente falida em alguns meses.

Durante muito tempo, os economistas neoliberais justificaram a alta das taxas de juros pela falta de capitais disponíveis e pela necessidade de retomar a poupança. A prova indireta de que as elevadas taxas de juros não foram mais do que um meio de transferência de renda de uma classe para a outra é dada pelo fato de que, contrariamente ao que previa o dogma, a taxa de poupança não parou de baixar, enquanto as taxas de juros subiam.

Autores pouco conhecidos por seu marxismo desenfreado, como Joseph Stiglitz proclamam o "fim do neoliberalismo". Depois das receitas keynesianas de políticas contracíclicas, os políticos ditos neoliberais estão, por sua vez, extenuados. Começamos - timidamente - a falar outra vez de regulação estatal. A Organização Mundial do Comércio - OMC só funciona aos soluços. O otimismo desenfreado cedeu espaço para a apreensão. Mas esta nova mudança de fase não é o anúncio de uma mudança radical. Aqueles que tinham julgado oportuno trocar o anticapitalismo pelo antiliberalismo correm o risco de se encontrar em uma situação desconfortável, se nos dirigirmos para um capitalismo autoritário com forte intervenção estatal, com o propósito de reprimir, antecipadamente, qualquer resistência popular. Em Berlim, e também em Nova Iorque, perguntam-se como fazer para se livrarem da democracia.

\section{A QUESTÃO DO VALOR}

Os teóricos da "Wertcritik" (crítica do valor) como Robert Kurz, Anselm Jappe ou Moishe
Postone propõem uma explicação global que faz, a partir da semente teórica do pensamento de Marx, a crítica do valor. A questão do valor ocupa a primeira seção de O Capital, uma seção que Althusser e seus discípulos julgaram ser obscura e contaminada pela escória do hegelianismo. É aí, contudo, que se amarra a crítica marxiana da economia política. O modo de produção capitalista não produz riquezas, ou seja, valores de uso; ele tem por motor a produção do valor, cujo corolário é a transformação do trabalho em trabalho abstrato. A contradição fundamental é a seguinte: no modo de produção capitalista, a riqueza se identifica com o valor e a grandeza do valor é "somente função do dispêndio do trabalho quando medido por uma variável independente (o tempo abstrato)". ${ }^{9}$ Ora, a dinâmica da produção do valor leva ao aumento da produtividade do trabalho (o que Marx analisa como mais-valia - ou sobre valor - relativa). Mas, no final, o aumento da produtividade - se ela ocasiona uma vantagem temporária para a fração do capital que dela se beneficia - não aumenta o valor. Se produzirmos duas vezes mais tecido em uma hora, o valor do metro do tecido simplesmente cai pela metade! Aliás, dito en passant, basta partir disto para se compreender o fundo da crise atual do modo de produção capitalista, o que evita perder tempo correndo atrás de fantasmas a especulação, os especuladores, os subprimes, etc. -, cada um, por sua vez, considerado como responsável pela crise. A própria dinâmica do capitalismo solapa a base sobre a qual repousa o capitalismo. Postone insiste: se, evidentemente, o antagonismo proletários/capitalistas desempenha um papel central, não é deste antagonismo que pode surgir uma perspectiva de inversão do modo de produção capitalista. A razão disso é que: “a luta de classes e o sistema estruturado pelo mercado de divisas não repousa em princípios opostos; este tipo de luta não representa uma perturbação em um sistema, de resto, harmonioso. Ela é, ao con-

Postone, Moishe, Temps, travail et domination sociale. Une interprétation de la théorie critique de Marx, traduzido do inglês por Olivier Galtier e Luc Mercier, éditions Mille et une nuits, p. 425. 
trário, inerente a uma sociedade constituída pela mercadoria como forma totalizante e totalizada". ${ }^{10}$

Proletários e capitalistas existem apenas em sua relação recíproca, no fundo como os dois polos desta forma geral que é o capital. O capital só pode ser abolido se for abolido aquilo que o produz, a saber, o trabalho abstrato, ou seja, o trabalho assalariado, fonte de valor. E, deste ponto de vista, as formas precisas da propriedade são, antes, indiferentes. O marxismo tradicional, que vislumbra a sociedade socialista como uma sociedade de trabalhadores assalariados por um empregador único, o Estado, permanece, então, dentro do quadro de submissão à lei do valor e, portanto, ao trabalho alienado. Do mesmo modo, a contradição não está entre as forças produtivas, cuja dinâmica própria, fundada sobre o trabalho e a cooperação, entraria em contradição com as relações de produção. As relações de produção, segundo a teoria de Marx, não são de modo algum externas às forças produtivas. A ideia de que o socialismo liberaria as forças produtivas controladas pela propriedade privada dos meios de produção não tem, tampouco, nenhuma relação direta com o pensamento de Marx (tal como expresso em O Capital):

Segundo a teoria crítica elaborada por Marx, abolir o processo cego acelerado de "crescimento" econômico e de transformação socioeconômica sob o capitalismo, bem como a natureza portadora de crise deste processo, exigiria a abolição do valor. Ultrapassar estas formas alienadas implicaria necessariamente em estabelecer uma sociedade fundada na riqueza material, uma sociedade na qual a produtividade aumentada levaria a um aumento correspondente da riqueza social. ${ }^{11}$

O que o desenvolvimento do capital abre é uma possibilidade, aquela de sua ultrapassagem invertendo o valor, ou seja, a dominação dos homens por seu próprio trabalho social e, a partir disso, uma revolução radical no que chamamos de trabalho. Não se trata do "crescimento ilimitado de

${ }^{10}$ Op. cit. p. 466

${ }^{11}$ Op. cit. p. 461 forças produtivas”, nem do “decrescimento”, mas de outro crescimento, aquele das possibilidades dos humanos se livrarem, o mais profundamente possível, das formas extenuantes, embrutecidas do trabalho, de não serem mais atados a uma divisão do trabalho cada vez mais desgastante. Trata-se, portanto, da possibilidade de uma verdadeira liberação, cuja ideia é guardada pelo capitalismo sob uma forma perfeitamente alienada:

o sonho contido na forma capital é aquele de uma absoluta falta de limite, de uma ideia de liberdade como liberação completa, no que se refere à matéria, à natureza. Este 'sonho do capital' se tornou o pesadelo para este e aqueles que o capital se empenha em liberar: o planeta e seus habitantes. A humanidade só pode despertar completamente deste estado de sonambulismo abolindo o valor. Esta abolição carregaria a necessidade que a produtividade tem de aumentar sem parar $[\ldots] .^{12}$

\section{O FUNDO DO PROBLEMA}

O capital se apresenta, então, como dinheiro que aumenta seu valor ao circular. Marx expõe em detalhe o mecanismo de exploração que torna possível este milagre. Por razões que são expostas ao longo das milhares de páginas de O Capital, ele conclui que o modo de produção capitalista só pode sobreviver pela acumulação do capital, o que supõe que o modo de produção seja perturbado incessantemente e que sejam continuamente descobertos novos campos de acumulação. A queda dos países do "socialismo real”, a conversão da China ao capitalismo e a emergência de novos atores principais como o Brasil deram um sopro real ao modo de produção capitalista durante as duas últimas décadas. Acreditou-se que a internet seria o futuro do capitalismo, mas a explosão da "bolha internet", no início dos anos 2000, marcou o fim destas esperanças. Por razões que seriam necessárias explicar mais detalhadamente, as novas técnicas da informação e da comunicação só podem acelerar, ainda mais, a queda da rentabilidade do capital, e sua

${ }^{12}$ Op. cit. p.561 
parte na produção total de valor só pode permanecer limitada. Podem-se vender automóveis pela internet e encontrar compradores. Internet ou não, é sobre as terras agrícolas, ou potencialmente agrícolas, que se concentra, cada vez mais, uma parte importante dos investimentos. Enfim, sob a pressão dos ecologistas ou do capitalismo verde, acreditou-se que o meio ambiente se constituiria em um mercado milagroso para as próximas décadas. Mas isso exige investimentos pesados que apenas os Estados poderiam assumir - ora, eles não podem mais realizar esta tarefa e, para adequar o habitat dos países ricos às normas de qualidade ambiental, seria necessário destruir milhões de habitações, em suma, produzir o equivalente a uma boa guerra com bombardeios aéreos!

Fundamentalmente, a continuação, a longo prazo, da acumulação do capital é um empreendimento quimérico por várias razões importantes e que precisam ser expostas aqui.

\section{O CRESCIMENTO DURADOURO IMPOSSÍVEL}

A financeirização e sua crise são apenas o meio empregado pelo modo de produção capitalista para realizar a mais-valia, que não é, ou ainda não é, produzida na "sala de máquinas" do modo de produção capitalista. A retomada do crescimento supõe a retomada da produção real do valor, portanto, do emprego de trabalho produtivo. Os neokeynesianos, mais ou menos socialistas, sustentam que o aumento de salários e a redistribuição de riquezas permitiria criar uma larga demanda solvente que retomaria o crescimento. Mas esta redistribuição de riquezas suporia intervir diretamente nos lucros. Ora, a crise do modo de produção capitalista não é uma crise de subconsumo, mas, fundamentalmente, uma crise do lucro. É por isso que os dirigentes dos grandes Estados e de instituições financeiras não acreditam mais nestas políticas de sustentação da demanda.

Mas admitamos que isso seja possível e que procedamos a uma eutanásia em massa dos rentistas. O problema seria recolocado de novo em um prazo mais ou menos próximo. Desenvolvimento durável ou não, não se pode aumentar a produção eternamente. O crescimento e a capacidade de resistência do modo de produção capitalista estão ligados às possibilidades de expansão que se abriram, em primeiro lugar, pelo colonialismo e, depois, pela integração no próprio núcleo da divisão mundial do trabalho de centenas de milhões de homens, até então deixados de lado. Estão ligados, também, a esta expansão intensiva que submete, progressivamente, todos os setores que escaparam da lei do capital (a economia familiar, o corpo, as relações sexuais, etc.). Mas, cedo ou tarde, esta expansão reencontrará seus limites. Primeiro, porque o planeta se acabou e não acreditamos que a Lua ou Marte possam, em um prazo razoável - e para um capitalista, o prazo razoável nunca é muito longo constituir-se em novos campos de acumulação do capital.

O capitalismo é revolucionário, por essência, e só pode subsistir na acumulação; ao mesmo tempo, esta acumulação ameaça a taxa de lucro e a própria existência do capitalismo. O capitalismo se desenvolve, então, necessariamente no conflito. Suponhamos um capitalista único - por exemplo, a concorrência chegou ao fim e só existe uma empresa, a empresa "Mundo S.A". Suponhamos, igualmente, que este capitalista único (poderia ser, também, um capitalista coletivo, uma assembleia de acionistas) disponha de meios de persuasão ou de coerção suficientes para se precaver contra eventuais concorrentes ou contra as revoltas dos dominantes. Tal capitalista não teria nenhum interesse em acumular capital e não estaríamos mais em um regime capitalista, mas em uma espécie de despotismo, como, talvez, as sociedades antigas tenham conhecido. Para existir, o capitalismo deve ser fracionado em capitais concorrentes. Mas a concorrência apenas executa as leis imanentes do modo de produção capitalista. 


\section{A QUESTÃO DEMOGRÁFICA}

O desenvolvimento do capitalismo sempre foi acompanhado de um desenvolvimento demográfico impetuoso. Toda sua história o atesta. Foi com seu potente impulso demográfico que a Alemanha, no início do século XX, reivindicou o primeiro lugar no concerto das nações e, sobre esta demografia, Hitler se fundamenta para reivindicar um "Lebensraum" para os alemães. As novas potências capitalistas (China, Índia, Brasil, mas também a Coreia, etc.) são nações jovens cuja população é numerosa. Inversamente, a relativa estagnação econômica do Japão ou de países europeus deve ser relacionada à sua demografia declinante.

Segundo a maior parte das estimativas, a população mundial deveria atingir seu máximo por volta de 2050, com 9 bilhões de habitantes. Nesta época, a população chinesa já teria começado a declinar seriamente, como consequência da política do filho único. Não haveria nenhum problema em si, para alimentar 9 bilhões de humanos; as terras cultiváveis continuam suficientemente vastas para isso, mas isso demandaria outra repartição de riquezas em escala mundial e é, sem dúvida, nisso que jaz o problema principal. Isso exigiria também e, talvez, antes de tudo, que os modelos de desenvolvimento econômico fossem radicalmente mudados. A prosperidade capitalista mundial repousa largamente sobre o dinamismo da economia chinesa, cujas taxas de crescimento entre $8 \%$ e $10 \%$ ao ano levaram consigo o sistema inteiro. Mas as consequências ecológicas disso já são desastrosas. Certos modelos preveem que, daqui até 2030, as terras que alimentam atualmente $65 \%$ da população chinesa se tornarão incultiváveis em virtude da poluição.

Mas há outra dimensão: uma população estagnada é, também, fatalmente, uma população que envelhece e há fortes chances de que o dinamismo global do modo de produção capitalista seja mortalmente atingido, mesmo que os outros problemas aos quais ele é confrontado encontrem uma solução ao menos provisória. A política do filho único na China foi um fator de crescimento (me- lhorando a relação população ativa/população total), mas ela vai trazer, a médio prazo (2030/2040), um contragolpe terrível. É, alias, por isso que os cenários que prolongam o crescimento chinês linearmente são totalmente irrealistas. A China é a segunda potência econômica mundial, mas só poderá alcançar os Estados Unidos em virtude do declínio destes. As perturbações que esta nova situação trará serão consideráveis, pois será uma transformação radical de condições da vida social. Se os maiores de 50 anos formam a maioria, de modo geral em todos os lugares, mecanicamente, o poder do conservadorismo será reforçado (vemos bem nos países da Europa) e os problemas sociais ligados à aposentadoria e ao sistema de saúde serão cada vez mais agudos. É inútil definir, aqui, cenários possíveis, mas, em todo caso, a questão da partilha das riquezas será colocada em um ângulo completamente novo - a menos que as classes dominantes procedam a um novo holocausto.

\section{RECURSOS LIMITADOS E CRISE AMBIENTAL}

Outro fator decisivo é aquele da rarefação de recursos, desperdiçados alegremente sob o regime da acumulação ilimitada do capital. Mesmo que as previsões dos ecologistas sejam, muitas vezes, exageradamente alarmistas - o deputado francês Cochet tinha previsto o fim do petróleo para os anos 2010-2020 -, todavia, as fontes de energia fóssil não poderão continuar sendo consumidas no ritmo atual. Os otimistas nos prometem petróleo ainda por uma centena de anos. Mas o problema é, sem dúvida, mais grave do que isso. A continuidade da acumulação do capital em larga escala suporia que os chineses e os indianos pudessem rapidamente ter acesso aos padrões de consumo europeus ou americanos. Ora, isso éfrancamente impossível. Se houvesse tantos automóveis na China quanto nos Estados Unidos, seria preciso, rapidamente, jogar a chave por debaixo da porta do Planeta Terra e procurar, eventualmente, algum exoplaneta um pouco mais acolhedor, mas esta perspectiva de ficção científica permane- 
cerá eternamente uma ficção científica.

Somos forçados a observar que outras fontes de energia existem. Os agrocombustíveis mobilizam, agora, quase $40 \%$ das terras agrícolas dos Estados Unidos, mas o maior produtor e exportador de etanol é o Brasil - onde, no entanto, uma parcela não insignificante da população continua subalimentada. Brasil e Estados Unidos produzem juntos 85\% do etanol mundial. Mas este filão está sendo hoje denunciado pelos especialistas do meio ambiente que mostraram que, em sua totalidade, é bem mais poluente do que os combustíveis fósseis e que sua rentabilidade final está longe de ser assegurada. Para não falar da pressão que esta produção exerce sobre a produção agrícola destinada à alimentação humana ou animal. Típico do modo de produção capitalista: enquanto alimentamos os 4x4 dos ricos, deixamos famintos os pobres. Os automóveis são mais bem cuidados do que os humanos.

As outras fontes de energia como os paineis fotovoltaicos ou os eólicos nunca permitirão substituir os combustíveis fósseis, visto que sua rentabilidade é hoje essencialmente devida ao fato de que os Estados ou as empresas de produção de eletricidade os financiam. No curso do mercado, essas energias alternativas nunca veriam a luz do dia, e é difícil imaginar os TGVs andando com paineis fotovoltaicos. Resta, evidentemente, a nuclear, mas que será, também, confrontada a médio prazo com a rarefação do combustível (urânio), e cuja recente catástrofe de Fukushima mostrou a extrema fragilidade e as ameaças que faz pesar sobre o planeta. Quanto ao domínio da fusão nuclear, é um assunto recorrente; ela é prometida para logo e permite justificar a continuação das pesquisas científicas que, de outro modo, teriam sido abandonadas há muito tempo; mas nada permite pensar que esta energia poderá ser, de fato, utilizável algum dia.

Os gadgets como o carro elétrico não resolvem, evidentemente, nenhum problema; ao contrário. Somente as propagandas governamentais e o ativismo das correntes ecologistas permitem o desenvolvimento destas produções, que não são alternativas diante da crise governamental, mas, antes, tentativas de fazer a indústria automobilística sair do seu marasmo.

A situação é semelhante para as fontes de matérias-primas. Desde já, a questão das terras raras (indispensáveis na fabricação de telas sensíveis ao toque, por exemplo) é a fonte de tensões entre a China (que detém praticamente o monopólio, de fato) e os outros países industriais. A pressão sobre as terras agrícolas continuará se agravando.

Se fizermos um balanço, o custo ambiental das "soluções" propostas para remediar a rarefação de recursos do planeta já é muito elevado. Basta evocar o caso da agricultura do Brasil com o desmatamento intenso, a redução drástica da biodiversidade, o triunfo das OGM, para se convencer disso. Mas é, sobretudo, o custo social, que já é enorme, e que será ainda maior no futuro.

Embora o aquecimento climático tenha desaparecido um pouco dos radares do sistema midiático e, embora estivessem sob os golpes da crise financeira, os Estados tenham globalmente decidido que era urgente não fazer nada, as questões permanecem. Se não é certo que as atividades humanas sejam o principal fator do aquecimento climático - sobre este ponto nos precipitamos, com frequência - e se é possível interrogar-se sobre a questão de saber se há um aquecimento a longo prazo (como o planeta, aliás, já conheceu) ou se se trata, apenas, de uma oscilação conjuntural; todavia, supondo que as ameaças anunciadas pelo GIEC e homologadas por várias conferências internacionais sejam sérias, são as condições de vida sobre a terra que serão subvertidas, notadamente, com o desaparecimento de milhões de quilômetros quadrados de terras habitadas, êxodos em massa de populações e de transtornos na agricultura que somos incapazes de prever.

As análises desenvolvidas pelo relatório de Meadows ${ }^{13}$ corroboram largamente com o que acaba de ser dito. Em uma entrevista para o jornal francês Le Monde, Meadows explica:

O crescimento vai parar em parte por conta da dinâmica interna do sistema e, em parte, em ra-

${ }^{13}$ Meadows, Dennis et alii, Les limites de la croissance, 2004, Éditions Rue de l'Échiquier, 2012. 
zão de fatores externos, como a energia. A energia tem uma grande influência. A produção petrolífera ultrapassou seu pico e começará a decrescer. Ora, não há nenhum substituto rápido do petróleo para os transportes, para a aviação... Os problemas econômicos dos países ocidentais são em parte devidos aos preços elevados da energia. Nos próximos vinte anos, entre agora e 2030, veremos mais mudanças do que aconteceu em um século, nos domínios da política, do ambiente, da economia, da técnica. Os problemas da zona do euro só representam uma pequena parte do que veremos. E essas mudanças não se darão de maneira pacífica. ${ }^{14}$

\section{A HUMANIDADE À BEIRA DO ABISMO}

Todas as questões que acabamos de abordar são bastante conhecidas. Mas há, ainda, outra. Marx dizia que o capital destrói suas duas fontes de riqueza, a terra e o trabalho. Mas chegamos, hoje, a um ponto em que a própria existência da humanidade está ameaçada. Durante muito tempo, tememos o holocausto nuclear: as grandes potências não tinham à sua disposição com o que destruir 10 ou 20 vezes o planeta? A ameaça é totalmente diferente hoje, embora não se possa descartar, definitivamente, a ameaça nuclear. É no próprio desenvolvimento das atividades "pacíficas" da alta tecnologia que residem os perigos mais graves, porque são os mais difíceis de perceber.

Comecemos pelas biotecnologias aplicadas ao homem, cujo desenvolvimento impetuoso se apoia em reivindicações - legítimas - em matéria de saúde. É no domínio da reprodução que estas técnicas levantam primeiro os problemas mais graves.

Peter Sloterdijk provocou um escândalo há alguns anos com uma conferência que se tornou um pequeno livro, Règles pour le Parc Humain ${ }^{15}$ [Regras para o Parque Humano]. Ele falava - embora isso não se constitua de modo algum no ponto central de sua proposição - de biotecnologias e tentava explorar algumas das questões angusti-

${ }^{14}$ Entrevista com Hervé Kempf e Stéphane Foucart, 25/ $05 / 2012$.

${ }^{15}$ Sloterdijk, Peter, Règles pour le parc humain: une lettre en réponse à la lettre sur l'humanisme de Heidegger, traduit par Olivier Mannoni, éditions Mille et une nuits, 2000. antes que nos são colocadas sob o impulso das novas possibilidades abertas. "Um dos traços característicos da condição humana, diz Sloterdijk, é de colocar os homens diante de problemas pesados demais para eles, sem que possam decidir não abordá-los em virtude do seu peso".

Sloterdijk evocava "um processo de civilização no seio do qual explode, de uma maneira aparentemente irreversível, uma onda de desinibição sem precedente”. Ele acrescentava uma questão muito mal compreendida: "Mas a evolução a longo prazo levará a uma reforma genética das propriedades da espécie - uma antropotecnologia futura atingirá o estágio de uma planificação explícita de características? A humanidade poderá conquistar, em toda a sua espécie, uma passagem do fatalismo dos nascimentos ao nascimento opcional e à seleção pré-natal?”

As interrogações de Sloterdijk (e de muitos outros filósofos ou moralistas) têm algo de paradoxal. O progresso técnico aumenta, não apenas nosso domínio sobre a natureza, mas promete, até mesmo, não deixar a geração de humanos ao acaso de encontros e à loteria da meiose. Ele aparece, então, como um progresso da liberdade, se a liberdade é a possibilidade de dominar nosso próprio destino, de ser menos submetidos a causas que não dependem de nós. Portanto, o domínio biológico do humano poderia surgir, em breve, como o prelúdio de uma transformação radical da condição humana, na qual a ideia de liberdade não teria nenhum sentido.

As questões ambientais (efeito estufa, preservação da biodiversidade, OGM, etc.) só têm nelas mesmas, uma importância relativa, já que são questões relativamente levantadas para o útil e o inútil. Mas a aplicação de técnicas de manipulação genética em humanos, o desenvolvimento da engenharia neural com a possibilidade de enxertar próteses eletrônicas no aparelho neural humano, ou as possibilidades abertas pelas nanotecnologias, tudo isso nos coloca, agora, à beira do abismo.

As novas tecnologias, que levantam problemas éticos graves, podem ser divididas esquematicamente em três grupos. 
1. Os procedimentos que permitem escolher os humanos que nascerão: a utilização da fertilização in vitro e transferência do embrião FIVETE - com triagem seletiva de embriões pela engenharia genética.

2. Os procedimentos que permitem controlar os cérebros humanos - em particular tudo o que gira em torno da química do cérebro.

3. Os procedimentos que permitem modificar diretamente a própria natureza humana, com a introdução de próteses eletrônicas como prolongamentos do cérebro e como meios de controle dos humanos.

Em todas as hipóteses, temos boas razões para desenvolver essas técnicas e suas vantagens são dificilmente contestáveis. Elas se inscrevem, além disso, na estrita continuidade da concepção de ciência que se esboçou no início dos tempos modernos. Ninguém deseja ter um filho que sofra de uma deficiência congênita, quando existem meios técnicos de evitá-lo. A "triagem seletiva” dos filhos a nascer existe, aliás, já há algum tempo. A detecção da trissomia 21 leva ao aborto em 99\% dos casos... Há muito tempo, admitimos que podemos modificar nossos estados cerebrais e mentais por meio de moléculas químicas.

O ácido acetilsalicílico, ao fluidificar o sangue, pode eliminar a dor. Os medicamentos químicos da depressão (Prozac, por exemplo) ou da esquizofrenia têm uso corrente e indiscutível. Se estivermos infelizes, o estímulo da produção de serotonina fará o serviço... As próteses prestaram inestimáveis serviços aos humanos, vítimas de acidentes, de guerras ou de doenças. Ninguém pensa que há o menor problema ético em usar óculos ou um aparelho auditivo! Se podemos, realmente, ajustar um "chip" que permitirá aos paraplégicos dirigir através do pensamento de um robô, qual é o mal nisso? Afinal de contas, a técnica imita a natureza ou a supre onde ela não é forte o bastante, já disse Aristóteles.

O que nos leva a aceitar, e mesmo desejar, o progresso ilimitado do domínio técnico sobre o humano é a ilusão da continuidade. No fundo, o argumento clássico é esse: se não querem modifica- ções programadas do genoma humano, não era preciso se ter inventado nem o fogo nem a roda! Voltem, portanto, a andar de quatro patas. Essa já foi, afinal, a resposta de Voltaire a Rousseau. Mas este argumento de "bom senso" aparente é falacioso. Ele esquece simplesmente que, como diziam os velhos marxistas que acreditam ter lido isso em Marx, "a quantidade se transforma em qualidade".

Todos os progressos técnicos anteriores, da máquina a vapor à energia nuclear, do telégrafo de Chappe à internet, da cirurgia de Ambroise Paré à microcirurgia moderna, etc., mantêm intacto o homem em si. Se a energia nuclear, pela primeira vez na história, coloca nas mãos do homem a possibilidade de uma autodestruição da espécie humana (e de muitas outras espécies a título de efeitos colaterais), ainda é, fundamentalmente, um homem idêntico a seus ancestrais caçadores-coletores que pode ser destruído. Com as biotecnologias, é a própria identidade da espécie humana que está em jogo.

Trata-se, antes de tudo, portanto, da substituição da fabricação do humano pela procriação. As técnicas que permitem a escolha do sexo da criança que vai nascer foram largamente difundidas. Do aborto após a ultrassonografia até a FIVETE, temos meios de seleção cada vez mais aperfeiçoados. Mas ainda estamos presos à seleção do que é produzido pelo acaso, pelo processo aleatório da meiose. A fase seguinte é a da intervenção direta no genoma humano, ou seja, de uma produção diretamente pilotada $a b$ initio do embrião humano, uma ideia que não existe sem remeter à contrautopia de Aldous Huxley em Admirável Mundo Novo (A brave new world). A engenharia genética, para além dos mitos e crenças mais ou menos racionais, para além das tomadas de posição religiosas, está dentro da própria lógica do desenvolvimento do capitalismo: trata-se de difundir, em todos os lugares onde for possível, a transformação de atividades vitais em produção de mercado e, ao mesmo tempo, continuar, até o fim, o processo propriamente mortífero típico deste modo de produção. Este processo é analisado por Marx na transformação do trabalho vivo em trabalho morto. 
O conceito de trabalho morto, desde que tenhamos esboçado sua demonstração, é inseparável de outro conceito, desenvolvido, sobretudo por Lukács e seus discípulos, o conceito de reificação. Embora este conceito de reificação não tenha sido desenvolvido por Marx, mas por alguns de seus discípulos menos conformistas aqueles que souberam, ao menos parcialmente, ficar livres do julgo do marxismo oficial - como Lukacs ou certos filósofos da "Escola de Frankfurt". Para Lukacs, a reificação designa, em primeiro lugar, a colonização do mundo vivido pelas representações impostas pela dominação do valor. ${ }^{16}$ Mas, se a palavra não está em Marx, a coisa está. No capítulo I,IV de $O$ capital, consagrado à análise do fetichismo da mercadoria, está claramente exposto do que se trata. No senso estrito, o fetichismo consiste no fato de se dar um valor sagrado a um ser de nosso mundo. Quando Marx fala do caráter fetiche da mercadoria, é em relação com as análises antropológicas que tratam disso. $\mathrm{O}$ fetichismo da mercadoria torna o valor e sua encarnação monetária a verdadeira potência viva, transformando o trabalho vivo em coisa, tornando os trabalhadores significativamente em "recursos humanos". A transformação da vida em processo de fabricação tecnocientífica coroa, portanto, esta dinâmica interna do modo de produção capitalista.

Se a colonização das consciências em grande escala e com a ajuda das ciências sociais é uma das partes - e não das menores - da modernidade capitalista, ${ }^{17}$ é, atualmente, através dos meios da biologia e das técnicas de informática que este processo continua. Trata-se, claro, do tratamento intensivo de dados pessoais pelas redes sociais ou dos vendedores pela internet (como o Amazon). Trata-se, também, da intrusão direta no cérebro humano com a pesquisa de uma espécie de máquina de ler pensamentos, que enviaria para a préhistória os bons e velhos detectores de mentira da polícia. A IBM anuncia tal máquina para 2017, o

${ }^{16}$ Lukacs, Georg, Histoire et conscience de classe. Essais de dialectique marxiste, éditions de Minuit, 1960.

${ }^{17}$ Sobre este aspecto ver o livro de Remo Bodei, Destini personali. L'età della colonizzazione delle coscienze, Milan, Feltrinelli, 2002. que é, sem dúvida, muito otimista, mas os trabalhos neste sentido já ocupam inúmeros pesquisadores. Evidentemente, como sempre, o pior recebe os adornos cintilantes do melhor: poderemos nos comunicar com o cérebro de indivíduos que sofrem de paralisia total ou que estão profundamente em coma.

Para completar estes projetos extravagantes, trabalha-se, também, intensamente sobre o ciborgue, ou seja, sobre a possibilidade de enxertar dispositivos eletrônicos no cérebro humano, com vistas a obter um "humano melhorado". É o prenúncio do pós-humano que deixou as prateleiras de ficção científica das livrarias para tornar-se um objetivo de pesquisa. Muitas universidades já oferecem diplomas de ciborgologia (sic). Em todos estes projetos, reconheceremos, facilmente, a fantasia da onipotência daqueles que se consideram Deus. Mas, enquanto o Deus de Abraão tinha criado o homem à sua imagem e semelhança, ou seja, livre, o capital transforma o homem em coisa não livre, em engrenagem pura e simples da acumulação do capital, que se torna a força viva. "Não se para o progresso", diz o provérbio. Mas o "progresso" se resume, hoje, a esta transformação intensa do poder pessoal dos homens em trabalho morto, em trabalho coagulado, que ameaça toda a civilização humana.

Pois a continuidade do desenvolvimento do modo de produção capitalista não projeta outro futuro que não seja o de uma nova barbárie, da qual já temos algumas percepções sob os olhos: na pretensa "cultura" que emerge dos jogos de vídeo, quase todos os jogos de guerra que conectam atualmente mais de 10 milhões de jogadores do mundo inteiro - visto o célebre World of Warcraft -; no desenvolvimento de uma sociedade de vigilância generalizada e na destruição da privacidade; na mecanização da literatura, produzida industrialmente e destinada, prioritariamente, a jovens "cérebros disponíveis"; mas, também, em uma vida cada vez mais submetida às exigências de um consumo desprovido de sentido, a ponto de os indivíduos se parecerem, cada vez mais, com estes hamsteres que fazem girar a roda de sua gaiola até a morte. 


\section{OUTRA VEZ A QUESTÃO DA CRISE}

Assim, a crise que enfrentamos, longe de ser uma questão para os economistas e os tecnocratas, únicos a definir “a boa gestão", é, verdadeiramente, uma crise da humanidade em todas as suas dimensões. Durante milênios, os homens estavam, antes, preocupados com o processo de seu ciclo vital: como assegurar o alimento do dia seguinte, como se proteger da natureza, como garantir a perpetuação da espécie humana. Hoje em dia, o meio empregado para assegurar este processo vital, o modo de produção capitalista, se volta contra a própria vida. Expulso da universidade pelos nazistas, Husserl escreverá um de seus mais belos textos consagrados à "crise da humanidade europeia”. ${ }^{18}$ Não se trata mais, atualmente, apenas da humanidade europeia, mas da humanidade pura e simplesmente. E esta crise exige bem uma tomada de consciência, a mais lúcida e mais radical e a preparação metódica de uma alternativa contra a barbárie que vem.

Recebido para publicação em 01 de setembro de 2012 Aceito em 04 de novembro de 2012

\section{REFERÊNCIAS:}

BODEI, Remo. Destini personali. L'età della colonizzazione delle coscienze. Milan: Feltrinelli, 2002.

BOUKHARINE, Nicolas. L'économie politique du rentier. Critique de l'économie marginaliste. Réédition Syllepse, 2010.

GALBRAITH, John K. La crise économique de 1929. Éditions Payot, 1989.

HUSSERL, Edmund. La crise des sciences européennes et la phénoménologie transcendantale. Traduit de l'allemand, Gallimard, 1976.

HUSSON, Michel. Les trois dimensions du néoimpérialisme. In: Revue Actuel Marx, n. 18, PUF, 1995.

LUKACS, Georg. Histoire et conscience de classe. Essais de dialectique marxiste. Editions de Minuit, 1960.

MARX, Karl. Le Capital. Livre III. Édition de La Pléiade, tome 2. Gallimard, 1968.

MEADOWS, Dennis et al. Les limites de la croissance. 2004. Éditions Rue de l'Échiquier, 2012.

POSTONE, Moishe. Temps, travail et domination sociale. Une interprétation de la théorie critique de Marx. Traduit de l'anglais par Olivier Galtier et Luc Mercier. Éditions Mille et une nuits, 2009.

SLOTERDIJK, Peter. Règles pour le parc humain: une lettre en réponse à la lettre sur l'humanisme de Heidegger. Traduit par Olivier Mannoni. Éditions Mille et une nuits, 2000.

18 Ver La crise des sciences européennes et la phénoménologie transcendantale, Gallimard, 1976, uma obra que contém a conferência de Viena de 1935, La crise de l'humanité européenne et la philosophie. 


\section{THE CRISIS OF HUMANITY AND RADICAL LA CRISE DE L'HUMANITÉ ET LA CRITIQUE CRITIQUE OF VALUE \\ RADICALE DE LA VALEUR}

\section{Denis Collin}

The current crisis is not simply an economic crisis. It is a global crisis that affects all aspects of human life on a worldwide scale. The system based on the unlimited accumulation of capital can no longer be perpetuated without threaten civilization itself. In this sense, it is a crisis of mankind, much more than an economic crisis. The resumption of marxians key concepts allows us to understand its seriousness and depth.

KEY WORDS: Accumulation of capital. Agriculture. Crisis.

\section{Denis Collin}

La crise actuelle n'est pas qu'une simple crise économique. Il s'agit d'une crise globale qui touche à tous les aspects de la vie humaine à une échelle mondiale. Le système basé sur l'accumulation illimitée du capital ne peut plus être perpétué sans menacer la civilisation ellemême. Dans ce sens, c'est une crise de l'humanité bien plus qu'une crise économique. Reprendre les concepts-clés de Marx nous permet de comprendre combien elle est grave et profonde.

Mots-CLÉs: Accumulation du capital. Agriculture. Crise. Règlement. Système monétaire international.

Denis Collin - Doutor em Literatura e Humanidades. Professor da Université de Rouen et Lycée Briand Évreux. Filósofo. Ensina num liceu em Évreux e preside a Universidade Popular na mesma cidade. Tem muitas obras publicadas, como La fin du travail et la mondialisation: Idéologie et réalité sociale, La théorie de la connaissance chez Marx, Comprendre Marx, este traduzido para o português. Sobre Marx e a crise, publicou Le cauchemar de Marx e o último, e talvez, o mais importante de seus livros, La longueur de la chaîne: essai sur la liberté au XXIe siècle. 
